\title{
Intercultural Competence in Short-Term Study Abroad
}

\author{
Annie Nguyen \\ York College of Pennsylvania
}

\begin{abstract}
:
Assessment is growing for short-term study abroad as the majority of students $(63.1 \%)$ continue to choose this option (Institute of International Education, 2016). This study uses the Intercultural Effectiveness Scale (IES) to examine the impact of short-term study abroad programs on students' overall intercultural competency and the connections between those measured areas and programmatic content. Using the IES survey distributed before, after, and three months following the study abroad experience, data was analyzed for fifty-five students across eight different shortterm programs at three distinct institutions within the state of Texas. Document analysis of program syllabi looked at connections to structured activities and assignments. The results demonstrate significant impacts on students' self-perceived intercultural competency in short-term study abroad programs ranging from two to five weeks that appear associated with intentional programmatic structures. These findings support recommended practices of using well-defined activities and assignments, incorporating meaningful local interaction, and providing planned reentry.
\end{abstract}

\section{Introduction}

Study abroad programs are often thought of for language learning and semester to yearlong sojourns, but increasingly short-term study abroad programs are becoming the option of choice for many students (Hulstrand, 2006; IES Abroad, 2011; Institute of International Education, 2011; Kehl \& Morris, 2007). In the most recent figures released by the Institute of International Education (2016) in its Open Doors Report, 313,415 university students studied abroad for credit during the 2014-2015 academic year, 274,551 of which were undergraduate students. Among the various programs, $63.1 \%$ of them were considered short-term which include summer term at 39\%, January term at $7.4 \%$, and programs during the academic term that are eight weeks or less at $16.7 \%$. This figure has risen more than $10 \%$ over the last ten years with the greatest gains being in programs during the academic year that are eight weeks or less, up 8.7\% (Institute of International Education, 2016).

The growth and frequency of short-term study abroad begs the question, how are those experiences being developed in ways that complement the goals of intercultural competence? Many higher education institutions have begun including intercultural competence as one area of evaluation following the rise in discourse around such goals (Bok, 2006; Deardorff, 2011; Deardorff \& Hunter, 2006; Green, 2012; Javidan \& Bowden, 2013; Stebleton, Soria, \& Cherney, 2013; Vande Berg, Connor-Linton, \& Paige, 2009). This study uses the Intercultural Effectiveness Scale (IES) to examine the impact of those short-term study abroad programs on students, both on a quantitative 
scale and by analyzing connections between those measured intercultural competencies and programmatic content. The following research questions guided this work: (1) What gains (as measured by the IES), if any, are made in students' intercultural competence following participation in a short-term study abroad program? and (2) In what ways are those competencies measured by the IES connected to structured programmatic content?

\section{Background}

"Given the growing importance of intercultural competence within postsecondary education, it becomes imperative to more closely examine what this concept is and how best to assess it in our students" (Deardorff, 2011, p. 65). An ample body of research has been conducted on topics within international education and study abroad. Three major themes are connected to this research: 1) the objective of intercultural competence; 2) assessment research on short-term study abroad; and 3) ways that program interventions are associated with gains in study abroad. The literature here provides a foundation for understanding intercultural growth specific to short-term study abroad program models.

\section{Intercultural Competence}

In a very broad sense, researchers agree that intercultural competence involves that ability to adapt behavior and communication to intercultural contexts using a variety of skills and knowledge (Bennett, 2009; Bird, Mendenhall, Stevens, \& Oddou, 2010; Deardorff, 2006; Deardorff, 2011; Gertsen, 1990; Schaettim, Ramsey, \& Watanabe, 2009). To assess development, intercultural competence is commonly broken down into cognitive, affective, and behavioral skills that allow a person to effectively adjust to other cultural situations (Association of American Colleges and Universities, 2010; Bennett, 2009; Bird et al., 2010; Deardorff, 2006; Deardorff, 2011; Gertsen, 1990; Schaettim et al., 2009).

According to Behrnd and Porzelt (2012), "the challenge of measuring intercultural competence is, besides the lack of a single commonly used definition, the assessment of not only knowledge and skills but also of attitudes and awareness" (p. 215). This has led to the development of a variety of quantitative assessment tools, such as those listed by Bird and Stevens (2013): Kelley and Meyers' (1995) Cross Cultural Adaptability Inventory (CCAI); Hunter's (2004) Global Competence Aptitude Assessment (GCAA); Bird, Stevens, Mendenhall, Oddou, and Osland's (2008) Intercultural Effectiveness Scale (IES); Hammer and Bennett's Intercultural Development Inventory (IDI) based on Bennett's theory (1993), the Development Model of Intercultural Sensitivity (DMIS); van der Zee and van Oudenhoven's (2000) Multicultural Personality Questionnaire; van der Zee and Brinkman's (2004) Intercultural Readiness Check; Earley and Ang's (2003) Cultural Intelligence (CQ) assessment; and Costa and McCrae's (1985) Big Five Personality Inventories. To guide those assessments at an institutional level, the Association of American Colleges \& Universities (AAC\&U) (2010) worked on the Intercultural Knowledge and Competence VALUE Rubric.

Intercultural Effectiveness Scale (IES). What Mendenhall, Stevens, Bird, Oddou, and Osland (2012) describe as a less complex version of the Global Competencies Inventory (GCI), which focuses on global leadership skills in the workforce, IES emphasizes those competencies that it considers necessary for intercultural effectiveness (p. 6). The instrument was designed to evaluate an individual's ability to interact "effectively with people who are from cultures other than [their] 
own" (Intercultural Effectiveness Scale, 2013). In line with many of the learning outcomes at institutions and within the AAC\&U (2010) VALUE rubric, the IES profiles specific skillsets that include three dimensions each with two subscales, assessing six competencies of intercultural effectiveness that will be described further within the methodology.

\section{Assessment of Short-Term Study Abroad}

While duration may be a factor, for studies involving short-term programs, gains were still seen in a variety of contexts (Anderson, Lawton, Rexeisen, \& Hubbard, 2006; Chieffo \& Griffiths, 2004; Dwyer, 2004; Jackson, 2008; Lewis \& Niesenbaum, 2005a, Richards \& Doorenbos, 2016). Two studies considered intercultural development as measured in pre-/post-test research designs using the Intercultural Development Inventory (IDI) (Anderson et al., 2006; Jackson, 2008). Anderson et al. (2006) studied American students participating in a four-week, non-language learning program to England and Ireland. Conclusions found that overall gains in intercultural sensitivity were weak. In terms of strong statistical support, Anderson et al. (2006) found that "as a group, the students lessened their tendency to see other cultures as better than their own (Reversal) and improved their ability to accept and adapt to cultural differences (Acceptance/Adaptation)" (p. 464). Even though the gains in overall IDI scores were minimal, the subscale changes were significant. Though not necessarily generalizable to American students, Jackson (2008) also observed Chinese students competent in English and traveling to England for five weeks, all of whom had minimal to no previous travel experience. Again, Jackson (2008) found that the IDI illustrated that students developed greater empathy and a more complex understanding of other cultures. Although the exact skills or components of intercultural competence were not examined in these studies, Jackson (2008) notes the usefulness of the IDI as a mentoring tool for understanding levels of development in students' intercultural skills and comments that 'intercultural learning is a challenging process that students need to work on before, during, and after a study abroad experience, no matter the length of the sojourn" (p. 357).

Studies using other survey instruments also found that "short-term programs, even as short as one month, are worthwhile educational endeavors that have significant self-perceived impacts on students' intellectual and personal lives" (Chieffo \& Griffiths, 2004, p. 174). Evaluating international awareness and activities, Chieffo and Griffiths (2004) found significant differences in the perceived learning outcomes of those who participated in short-term study abroad programs and those who remained on campus. Similarly, Lewis and Niesenbaum (2005a) asked survey questions related to the influence a short-term service learning program in Costa Rica had on students' subsequent academic, professional, and personal lives. While not specific to intercultural competence, these additional studies support increases in areas of intercultural awareness and functional knowledge (Chieffo \& Griffiths, 2004) as well as interdisciplinary study and issues related to globalization (Lewis \& Niesenbaum, 2005a).

In a study of participants in programs operated by the Institute for the International Education of Students, Dwyer (2004) reported a longitudinal study on a wide range of programs that used an Institute developed survey with findings "across five areas: general findings, academic attainment, intercultural development, career impact and personal growth" (p. 154). This study compared full year study abroad to semester long study abroad to summer term study abroad of six weeks in duration (Dwyer, 2004). While full year study abroad had a more sustainable and significant impact 
than other programs, across several elements summer programs showed a greater impact than semester long programs. Dwyer (2004) posits that the growth in shorter programs might be explained by careful, well-planned implementation.

The IES itself has been used in a number of ways, including understanding intercultural profiles of international graduate students (Robinson, Harrington, Cartwright, \& Walsh, 2017), pre/post-test studies on globally focused on-campus courses (Feng, 2016; Fish, 2013), and pre-/posttest research for semester long programs that include both local Malaysian students and international students (Gowindasamy, 2017). For short-term research, Richards and Doorenbos (2016) used the IES and the Intercultural Sensitivity Scale (ISS) in a pre-/post-test study on eighteen students participating in a three-week health seminar course. In this case, efforts were made in pre-departure to develop personal growth plans guided by the IES. While there was upward movement in students' overall IES, the study found no statistical significance for both the IES and ISS.

\section{Program Interventions}

Hunter (2008) stresses that programs will be more effective if they "do not rely on the haphazard chance of students engaging in this process on their own, but instead very intentionally organize learning activities to encourage it" (p. 99). Such comments are echoed by research that student growth in intercultural competence will not just happen naturally by being immersed in another culture (Behrnd \& Porzelt, 2012; Deardorff, 2011; Hunter, 2008; Pedersen, 2010; Vande Berg, Paige, \& Lou, 2012). Behrnd and Porzelt (2012) critique the current system of study abroad, particularly the "decision makers at universities [who] often ignore this fact and are not aware that intercultural learning by being abroad works only under certain conditions" that include meaningful preparation and intercultural training (p. 213).

Educational interventions can be used to enhance study abroad experiences both during the course itself and as part of a larger sequence before, during, and after. Within the study abroad experiences, Vande Berg et al. (2009) found several program features related to gains in intercultural development: duration, content coursework in the language of the host country, targeted language courses, mixed population of American and host country students, group mentoring, perceptions of a dissimilar culture, student housing, more time spent with host families or host nationals, and minimal time spent with American nationals (pp. 20-24). While the focus of Vande Berg et al. (2009) research was connected to language learning and longer study abroad durations, one notable intervention was the use of a cultural mentor onsite (p. 25). Pedersen (2010) showed similar findings where students who participated in "intercultural pedagogy" during their study abroad experience had greater gains than students who studied abroad without such intervention (p. 76). These studies point to the use of onsite interventions like structured learning or cultural mentoring as a significant part of study abroad program development. Such research speaks to the advantage of guided reflection during study abroad.

Beyond the study abroad experience alone, many institutions are looking for ways to support and integrate these programs before and after the experience. Deardorff (2011) encourages sufficient preparation for students on intercultural learning before study abroad opportunities take place so students can better communicate the growth occurring during these programs (p. 71). For those returning from study abroad, Behrnd and Porzelt (2012) surveyed a group of German 
students to explore the utility of intercultural training as a follow up to education abroad experiences. Duration was found to be a significant factor, but in terms of continued intercultural training Behrnd and Porzelt (2012) found that "the experience of having been abroad seems to have created the optimal precondition to benefit from intercultural training" (p. 220). In that regard certain features of intercultural training may benefit from use in combination with other education abroad programs. Huq and Lewis (2012) illustrate this mentality with the Global Orientation (GO!) initiative at University of North Carolina at Chapel Hill. The focus of the GO! Program is to provide students with "comprehensive intercultural and ethical training prior to their departure and after their return" (p. 46) to help students get the most out of their cultural experiences.

\section{Methodology}

This study focused on student growth and activities occurring in short-term programs. Using an assortment of eight short-term study abroad programs from three different higher education institutions, the following quantitative research took place over the course of nine months and involved pre-testing, post-testing, and follow up as recommended by Vande Berg (Medina-LópezPortillo, 2004, p. 191). The Intercultural Effectiveness Scale (IES) was used as the quantitative survey instrument that provided assessment of overall intercultural competency (and underlying competencies). In addition to the IES, course syllabi were examined to analyze each program's structured study abroad activities and make connections between the IES competencies and program content.

\section{Selection of Instrument}

Considering the length of these study abroad programs, the IES was chosen to examine specific areas of intercultural competence and program content by dividing the concept of intercultural effectiveness (a measure of overall intercultural competency) into six competencies. Developed by the Kozai Group, the IES is a sixty-item survey that takes approximately ten minutes to complete and generates an in-depth graphic profile (Bird \& Stevens, 2013; Mendenhall et al., 2012). Survey items are self-reporting statements written for responses to a five-point Likert format, ranging from 'Strongly Disagree' to 'Strongly Agree' (Mendenhall et al., 2012, p. 13). Not only do the group and individual feedback reports generated from the IES cover three critical dimensions to intercultural effectiveness, but each dimension includes two intercultural competencies that are similar to the competence objectives set out by AAC\&U (2010) and other institutions. Below is a brief description of each dimension and its relevant competencies as summarized from the IES Technical Report (Mendenhall et al., 2012):

Continuous Learning: The assessment of an individual's curiosity in learning about other cultures and about themselves.

- Self-Awareness - Measures the degree of awareness concerning strengths and weaknesses, personal worldviews, and the impact of past experiences and relationships with others.

- Exploration - Measures openness and active pursuit of learning about new and different ideas, values, and norms.

Interpersonal Engagement: The assessment of an individual's interest in understanding people with other viewpoints and developing meaningful relationships with different people. 
- Global Mindset-Measures the degree of interest in learning about different cultures and the people that make up those cultures.

- Relationship Interest - Measures the degree of effort people are willing to put into maintaining relationships with people from other cultures.

Hardiness: The assessment of an individual's capacity to cope with the psychological and emotional stress of interacting with people from other cultures.

- Positive Regard-Measures the degree to which an individual will generally view other cultures in a positive light.

- Emotional Resilience - Measures the degree to which an individual has the mental strength to handle challenging intercultural situations. (pp. 7-12)

\section{Selection of Participants}

Participants drew from accredited higher education institutions in Texas invested in developing study abroad experiences and representing three types: a mid-sized private university, a large regional public university, a large national public university. From each institution, two to three short-term study abroad programs were used with efforts made to obtain a similar number of participants per course. Programs were chosen based on the following criteria: undergraduate study abroad programs, eight weeks or less in the summer term, and non-language learning or service learning. Eventually, eight programs ranging from two to five weeks were used. Three each were from the mid-sized private university and large regional public university and two were from the large national public university. From those programs, a total of eighty students consented to this research and were asked to participate in the IES surveys to examine perceived gains in intercultural competency pre, post, and three months following their study abroad experience.

\section{Data Collection}

Intercultural Effectiveness Scale (IES). The IES was distributed online to all participants in the eight programs selected for this study. Participants took the IES three times: once before, once immediately after, and once three months following the study abroad experience. Table 1 outlines the response rate for participating programs, which had fifty-seven of the eighty students completing the survey all three times. This provided a combined response rate of $71.25 \%$ for the initial pre-trip survey. Students who did not complete the pre-trip survey were not contacted for any subsequent surveys. While there were fifty-seven respondents, two participants were excluded from the analysis of the findings leaving fifty-five total students. One student was participating in the cross-listed graduate level course as a doctoral student and one whose responses in the follow up survey were not completed in good faith.

Program structure and content. To better understand the IES data as a part of these shortterm study abroad experiences, it was important to contextualize how each program structured their activities and assignments. The syllabi for each of the eight programs were collected before the distribution of the IES to provide a frame for the types of activities and assignments expected. These activities and assignments were confirmed with participants following the study abroad experience to note any changes that may have occurred during the program. 
Table 1. Response Rate in Participating Programs

\begin{tabular}{|l|c|c|c|c|c|c|}
\cline { 2 - 7 } \multicolumn{1}{c|}{} & Duration (Days) & Location & Field of Study & $\begin{array}{c}\text { Participant } \\
\text { Pool }\end{array}$ & $\begin{array}{c}\text { Students } \\
\text { Respondents }\end{array}$ & $\begin{array}{c}\text { Response } \\
\text { Rate }\end{array}$ \\
\hline \multirow{2}{*}{$\begin{array}{l}\text { Mid-sized } \\
\text { Private }\end{array}$} & 14 & Peru & Business & 21 & 13 & $61.90 \%$ \\
\hline \multirow{3}{*}{ Large Regional } & 21 & Ghana & Humanities & 8 & 7 & $87.50 \%$ \\
\cline { 2 - 7 } & 16 & France; Netherlands & Life Sciences & 6 & 6 & $100.00 \%$ \\
\hline & 26 & China & Social Sciences & 13 & $6(5)$ & $46.15 \%$ \\
\hline \multirow{2}{*}{ Large National } & 35 & Italy & Fine Arts & 11 & 6 & $54.55 \%$ \\
\cline { 2 - 7 } & 31 & $\begin{array}{c}\text { Germany, Austria } \\
\text { Turkey, Germany, } \\
\text { Poland, Hungary, } \\
\text { Austria, Czech } \\
\text { Republic }\end{array}$ & Socilth Prournalism & 7 & $6(5)$ & $85.71 \%$ \\
\hline
\end{tabular}

\section{Data Analysis}

Intercultural Effectiveness Scale (IES). The IES data uses raw scores ranging from one to five based on a five-point Likert scale. For the fifty-five respondents, each of the ten IES components was analyzed using all survey participants in total and then again at the programmatic level. SPSS Statistics Software was used to conduct a repeated measures analysis of variance (ANOVA) on the total IES quantitative data to determine what gains, if any, are made over a time period spanning from before to three months following a short-term study abroad. At each interval, the data was reviewed for outliers. Standard deviations and means were then computed for each of the ten components of the IES: Overall IES as a measure of total intercultural competency, Continuous Learning (Self-Awareness, Exploration), Interpersonal Engagement (Global Mindset, Relationship Interest), and Hardiness (Positive Regard, Emotional Resilience) (Mendenhall et al., 2012, pp. 7-12). These means considered each pre, post, and follow up interval. Paired sample $t$-tests were used for post-hoc analysis comparing pre to post, post to three months, and pre to three months. At the programmatic level, non-parametric analyses were run using a Friedman's analysis of variance with Wilcoxon Signed Rank Test for post-hoc comparison.

Program structure and content. While IES provided a broad view of the study abroad experience, program syllabi offered a look at programmatic design and how activities were connected to each of the six IES intercultural competencies. The structured activities and assignments speak to the academic nature of the program which distinguished the experience from other travel. From the program syllabi, coding was done to connect activities and assignments described to related competencies. Based on the IES definitions and survey items, each assignment or activity was coded as connecting to at least one of the competencies and in some case multiple competencies based on its major components. No single activity or assignment covered all six competencies, with most linking to between one to three areas.

Self-Awareness was coded for assignments or activities that indicated student reflection on their own experience or culture such as a student presentation on Texas culture in China or reflection journals students did during or after the experience. Exploration and Global Mindset were more difficult to separate and several activities touched on both. Exploration was coded in areas that had 
students out in new environments and able to explore new aspects of the culture. Global Mindset involved similar activities, but also included more specific lectures about cultural differences. Both dealt mainly with aspects of obtaining cultural knowledge and understanding cultural difference that are part of pre-trip exams, cultural site visits, and student reflections. Relationship Interest was coded for activities and assignments that encouraged connecting with local residents, for example roundtables or group projects with local students. Positive Regard was coded for activities that were specific to showing the local culture in positive light such as World Cup viewings or farewell dinners with local guests. Emotional Resilience is not something normally discussed in syllabi beyond references to "intensive"; in these instances, student commentary was used to confirm which activities were emotionally or physically taxing, such as all day travel through the Amazon in Peru or long project hours and difficulty in communicating with locals in Mexico.

\section{Limitations and Biases}

While this study offers many interesting elements in the evaluation of short-term study abroad programs, there are several limitations. Most significantly, it is limited in its generalizability. Though there were multiple programs representing a variety of frameworks used at different institutions in Texas, this research only focused on three institutions and the students of eight programs in a specific state. Moreover, the sample size at a programmatic level was relatively small. This was influenced by the number of students participating in this research but also by the number of students enrolled in general for each program which ranged from ten to twenty-three. While nonparametric analyses were used at the programmatic level, the same would be required even if every student from each program had consented to participate. Given the variety of context in the programs, faculty, and implementation of activities, findings may not be generalizable to other shortterm study abroad experiences.

Any assessment of the long-term effects of these experiences will go beyond the scope of this research, as the design of the study was limited in both time and types of activities examined. These short-term programs focused on those occurring in the summer as opposed to those in winter or during the school term. While types of activities were examined, the assessment of how those activities relate to specific intercultural competencies is limited by what is outlined in the syllabi. And though the research did as much as possible to not intervene, the act of collecting data may in itself influence some of the outcomes of the survey instrument. To minimize undue influence, outside of the survey, the study refrained from asking student participants to do more than is typical of their program; however, repeated exposure to the same survey may have affected student responses.

Lastly, the behaviors measured by IES are only one part of the equation, showing intercultural development and foundational skills. As a self-reporting instrument, the IES is restrictive in fully understanding intercultural competency as the concept of "appropriate behavior" in this case can only be observed through self-reflection by the traveler as opposed to from locals interacting with the traveler. Thus, while self-reporting instruments for intercultural competence are commonly used, there are concerns as to how those perceived personal gains will translate into equally appropriate intercultural behaviors if observed by others (Olson, Green, \& Hill, 2006). 


\section{Results and Discussion}

The development of students' intercultural competency and related competencies as measured by the IES Survey are presented in total and for each of the eight programs. Though each will be discussed further, these findings indicate measured gains in overall intercultural competency as driven by changes in three of the six competencies (Self-Awareness, Global Mindset, and Relationship Interest) and the ways that those particular competencies appear supported through structured experiences outlined within the program syllabi. What begins to emerge is the understanding that the changes occurring for these students are rooted in thoughtful and intentional decisions in program design.

\section{Development along the Intercultural Effectiveness Scale (IES)}

The IES survey was given at a schedule before, after, and three months following the study abroad experience. While the criterion for short-term programs was considered less than eight weeks, the longest program was only five weeks (Germany \& Austria) and the shortest programs were close to two weeks (Peru; China). Despite being in very different programs, all students are considered to have participated in a time-constrained, faculty-led international experience.

Overall findings. By and large, the fifty-five students participating in a short-term program demonstrate an upward trend in intercultural competency as defined by their overall IES mean scores. While the full range possible is from 1.00 to 5.00 , the mean scores for all ten IES components fell within the range of 2.60 and 4.40 (Table 2). Students were shown to have a starting mean score of 3.60 before their study abroad experience and a mean score of 3.74 afterwards. Even three months later, the mean score among students remained at 3.74. This movement seems to indicate that overall scores are influenced by short-term study abroad experiences in a positive way and remain at similar post trip levels three months later.

Table 2. Mean Scores for IES Components over Time

\begin{tabular}{|l|c|c|c|}
\cline { 2 - 4 } \multicolumn{1}{c|}{} & Pre & Post & Follow Up \\
\hline OVERALL IES & 3.60 & 3.74 & 3.74 \\
\hline Continuous Learning & 4.08 & 4.20 & 4.18 \\
\hline $\begin{array}{l}\text { Self-Awareness } \\
\text { Exploration }\end{array}$ & 3.90 & 4.03 & 4.04 \\
\cline { 2 - 4 } & 4.27 & 4.37 & 4.33 \\
\hline Interpersonal Engagement & 3.38 & 3.62 & 3.62 \\
\hline $\begin{array}{l}\text { Global Mindset } \\
\text { Relationship Interest }\end{array}$ & 2.73 & 3.17 & 3.06 \\
\hline Hardiness & 4.03 & 4.07 & 4.18 \\
\hline $\begin{array}{l}\text { Positive Regard } \\
\text { Emotional Resilience }\end{array}$ & 3.34 & 3.39 & 3.43 \\
\cline { 2 - 4 } & 3.31 & 3.39 & 3.42 \\
\hline
\end{tabular}

Looking deeper into the data, it is important to understand which dimensions affected the changes in overall IES scores. Although there was an upward trend as a whole, when examining each dimension in the context of changes in intercultural competencies, the movement took on an interesting shape. For Continuous Learning, the table shows upward movement overall and within each subscale followed by a slight dip three months later. For Hardiness, movement was mainly flat 
for all components with a slight increase. While there were gains (and losses three months later for some) among all the competencies, the biggest driver in gains appeared to be within the dimension of Interpersonal Engagement, with the largest movement in the subscale of Global Mindset.

The objectives for participating short-term programs all discussed expanding new cultural knowledge and/or understanding cultural difference in the context of various fields of study. Considering Global Mindset measures interest in other cultures based on actively seeking outlets for learning about them, the goals of each program worked to encourage development along this outcome. The lack of movement for Positive Regard and Emotional Resilience in such a short period could be expected, especially when some models (Deardorff \& Hunter, 2006; Kim, 2001) see this type of strength and positivity as a part of an individual's predisposition. Still, it was interesting to note that among all these subscales, one appeared to be driving change within short-term study abroad experiences.

Table 3. Repeated Measures ANOVA for IES Components for All Participants

\begin{tabular}{|c|c|c|c|}
\hline & $\mathrm{F}$ & $\mathrm{p}$ & $\eta 2$ \\
\hline OVERALL IES & 21.677 & $0.000^{*}$ & 0.286 \\
\hline Continuous Learning & 7.425 & $0.009 *$ & 0.121 \\
\hline \multirow{2}{*}{$\begin{array}{l}\text { Self-Awareness } \\
\text { Exploration }\end{array}$} & 8.334 & $0.006^{*}$ & 0.134 \\
\hline & 2.086 & 0.154 & 0.037 \\
\hline Interpersonal Engagement & 29.167 & $0.000^{*}$ & 0.351 \\
\hline \multirow{2}{*}{$\begin{array}{l}\text { Global Mindset } \\
\text { Relationship Interest }\end{array}$} & 26.533 & $0.000^{*}$ & 0.329 \\
\hline & 9.539 & $0.003^{*}$ & 0.150 \\
\hline Hardiness & 3.361 & 0.072 & 0.059 \\
\hline \multirow{2}{*}{$\begin{array}{l}\text { Positive Regard } \\
\text { Emotional Resilience }\end{array}$} & 0.911 & 0.344 & 0.017 \\
\hline & 3.392 & 0.071 & 0.059 \\
\hline
\end{tabular}

Note: $d f=1 ; *$ Significance at $p<0.05$ level

It is important to consider the significance of those changes within each of the competencies measured by the IES. Using SPSS, a repeated measures ANOVA was conducted with paired sample t-tests for post-hoc analysis. The repeated measures ANOVA is a more conservative test that reduces error when using three points in time; from which, overall significance of each scale was measured where $(\mathrm{p}<0.05)$. The paired sample t-tests used for post-hoc analysis compared pre to post, post to three months, and pre to three months. To account for increased possibility of error in running multiple tests, a Bonferroni correction was used in interpreting post-hoc significance using $(\mathrm{p}<0.017)$ to provide a more accurate reading. The resulting significance and effect size for each scale is shown in Table 3 and Table 4.

The development of intercultural competency as a measured by the overall IES score demonstrated significant gains $\left(F_{(1)}=21.677, p=0.000, \eta^{2}=0.286\right)$ following participation in a short-term study abroad experience that were sustained at a point three months later. These changes were influenced by shifts in two dimensions and three of the four intercultural competencies within them as defined by the IES: Continuous Learning $\left(F_{(1)}=7.425, p=0.009, \eta^{2}=0.121\right)[$ Self- 
Awareness $\left.\left(F_{(1)}=8.334, p=0.006, \eta^{2}=0.134\right)\right]$ and Interpersonal Engagement $\left(F_{(1)}=29.167, p=\right.$ $0.000, \eta^{2}=0.351$, $)$ [Global Mindset $\left(F_{(1)}=26.533, p=0.000, \eta^{2}=0.329\right)$, Relationship Interest $\left(F_{(1)}=\right.$ 9.539, $\left.\left.p=0.003, \eta^{2}=0.150\right)\right]$. Among those changes, it should be noted that the gains Global Mindset showed declined three months later, but still maintained a significant level of change from pre-trip levels. On the opposite end, Relationship Interest did not achieve significant gains until three months after the experience. While there may have been subtle shifts, there were no significant changes across time for the mean scores in one dimension and the three remaining intercultural competencies: Exploration and Hardiness (Positive Regard, Emotional Resilience).

Table 4. Paired Sample t-Tests for IES Components for All Participants

\begin{tabular}{|c|c|c|c|c|c|c|c|c|c|c|c|c|}
\hline & \multicolumn{3}{|c|}{ OVERALL IES } & \multicolumn{3}{|c|}{ Continuous Learning } & \multicolumn{3}{|c|}{$\begin{array}{c}\text { Interpersonal } \\
\text { Engagement }\end{array}$} & \multicolumn{3}{|c|}{ Hardiness } \\
\hline & $\mathrm{T}$ & $\mathrm{p}$ & $|\mathrm{d}|$ & $\mathrm{t}$ & $\mathrm{p}$ & $|\mathrm{d}|$ & $\mathrm{t}$ & $\mathrm{p}$ & $|\mathrm{d}|$ & $\mathrm{t}$ & $\mathrm{p}$ & $|\mathrm{d}|$ \\
\hline Pre to Post & -4.258 & $0.000 * *$ & 0.428 & -3.189 & $0.002 * *$ & 0.322 & -4.487 & $0.000 * *$ & 0.480 & -1.059 & 0.294 & 0.108 \\
\hline Post to Three Months & -0.174 & 0.862 & 0.018 & 0.503 & 0.617 & 0.050 & 0.060 & 0.952 & 0.005 & -0.585 & 0.561 & 0.074 \\
\hline Pre to Three Months & -4.656 & $0.000 * *$ & 0.478 & -2.725 & $0.009 * *$ & 0.277 & -5.401 & $0.000 * *$ & 0.473 & -1.833 & 0.072 & 0.208 \\
\hline & & & & \multicolumn{3}{|c|}{ Self-Awareness } & \multicolumn{3}{|c|}{ Global Mindset } & \multicolumn{3}{|c|}{ Positive Regard } \\
\hline Pre to Post & & & & -2.630 & $0.011 * *$ & 0.286 & -5.821 & $0.000 * *$ & 0.531 & -0.344 & 0.732 & 0.035 \\
\hline Post to Three Months & & & & -0.136 & 0.893 & 0.013 & 1.579 & 0.120 & 0.130 & -0.435 & 0.666 & 0.048 \\
\hline \multirow[t]{2}{*}{ Pre to Three Months } & & & & -2.887 & $0.006 * *$ & 0.284 & -5.151 & $0.000 * *$ & 0.392 & -0.954 & 0.344 & 0.091 \\
\hline & & & & \multicolumn{3}{|c|}{ Exploration } & \multicolumn{3}{|c|}{ Relationship Interest } & \multicolumn{3}{|c|}{ Emotional Resilience } \\
\hline Pre to Post & & & & -2.268 & 0.027 & 0.268 & -0.724 & 0.472 & 0.101 & -1.357 & 0.181 & 0.157 \\
\hline Post to Three Months & & & & 0.981 & 0.331 & 0.121 & -1.898 & 0.063 & 0.227 & -0.527 & 0.600 & 0.078 \\
\hline Pre to Three Months & & & & -1.444 & 0.154 & 0.165 & -3.089 & $0.003 * *$ & 0.372 & -1.842 & 0.071 & 0.245 \\
\hline
\end{tabular}

Note: $d f=54 ; * *$ Significance at $p<0.017$ level

The effect size of those changes revealed where students were most influenced. Drawing again from Tables 3 and 4, large effects where $\eta^{2}>0.14$ occurred for the Overall IES Score as driven mainly by the Global Mindset and somewhat by Relationship Interest in the dimension of Interpersonal Engagement. Components with intermediate effects, where $0.060<\eta^{2}<0.139$, were seen in SelfAwareness in the dimension of Continuous Learning. Digging further in the post-hoc, effect size of Cohen $|\boldsymbol{d}|$ was calculated for dependent $t$-tests; intermediate effects are seen as $0.5<|\boldsymbol{d}|<0.8$, small effects are $0.2<|\boldsymbol{d}|<0.49$, and no effects are considered at $|\boldsymbol{d}|<0.2$. This confirms that gains directly following the study abroad experience were the strongest in Global Mindset with intermediate effects pre to post, small effects pre to three months, and a large effect overall. Considering these scores across time and for components with significant changes, the only noticeable decline is in Global Mindset to the point that what was an intermediate effect became a small effect three months later. Showing a slightly different path, Relationship Interest, grew to a higher small effect three months later to become statistically significant. Generally, what can be seen is that participation in these short-term study abroad programs demonstrated significant gains in three of the six intercultural competencies defined by IES and were maintained with statistical significance or further developed to significance three months later-specifically, the Overall IES score, 
Continuous Learning (Self-Awareness), and Interpersonal Engagement driven by Global Mindset and with growth in Relationship Interest.

It is also important to understand what areas did not show significant changes. Within the IES movement, the competencies of Exploration, Positive Regard, and Emotional Resilience were not statistically significant; however, despite depicting minimal gains, those subscales did show mean scores trending upward. In fact, Exploration did show a strong upward trend immediately following the study abroad that dwindled three months after students returned. This may suggest that Exploration is aided by the immersive environment where everything is novel and students return actively pursuing new cultural information. Over time as familiar routines set in, it may dull the degree of exploration students are able to maintain. The period following the study abroad experience may require more support to facilitate growth in these areas toward more significant changes. Should programs wish to engage these particular competencies, it is likely that interventions specifically connected to those competencies are necessary.

Program comparisons. There were interesting trends when programs were parsed out; however, the number of students by program is quite small so observations from these findings are descriptive in nature. In general, each program depicted a similar path to the average scores for all fifty-five students with gains from pre to post followed by level or gradual decline three months later.

With programs as small as four and as large as thirteen, comparisons and significances used analyses that are the non-parametric equivalent to the repeated measures ANOVA and paired sample $t$-tests that were run on the total data pool. The data for each program was run through a Friedman's ANOVA analysis (Table 5) with subsequent post-hoc analysis employing the Wilcoxon Signed Rank Test examining pre to post, post to three months, and pre to three months. The results show significance within program changes in IES components overall at $95 \%$ confidence $(p<0.05)$. Due to the non-parametric nature, the post-hoc Wilcoxon Signed Rank analyses must also use the more conservative $\alpha=0.017$ (Bonferroni Correction) to be considered significant.

Peru, Italy, Mexico, and Germany and Austria showed significant gains in their Overall IES scores for intercultural competency. From a purely programmatic level, the table suggests intercultural competency (Overall IES Scores) was influenced mainly by changes in Global Mindset within the dimension of Interpersonal Engagement. Specifically, five programs showed varying patterns of significant change in Interpersonal Engagement with some form of influence from the subscale of Global Mindset: Peru, China, Italy, Mexico, and Europe. Three programs (Peru, China, and Italy) had statistically significant overall changes in Global Mindset, but only Peru showed a similar level of significance in the post-hoc tests.

Using Wilcoxon Signed Rank analyses, only Peru demonstrated changes of statistical significant in the post-hoc tests; however, this distinction does provide an interesting path comparison. Peru showed a significant change in Overall IES and Interpersonal Engagement from pre to three months, Self-Awareness from post to three months, and Global Mindset as the only area to be significant both pre to post and pre to three months. Considering that Peru was also the only program whose reflection activities were done after the experience, as opposed to during the study abroad, that may be the reason Self-Awareness did not show gains until three months later. China on 
the other hand was only approaching significance from pre to three months; Italy and Mexico were approaching significance pre to post, but fell short three months later. Furthermore, while this may be driven by the Global Mindset subscale, not all programs that showed significant overall changes in Global Mindset had analogous significance in changes to their Overall IES scores. Such variation may be due to other significant or approaching significant subscale changes, such as Self-Awareness for Peru; or minor upward trends in Exploration and Relationship Interest that when combined pushed overall changes to significance.

Table 5. Friedman's ANOVA for IES Components by Program

\begin{tabular}{|c|c|c|c|c|c|c|c|c|c|c|c|c|c|c|c|c|}
\hline & $x^{2}$ & $p$ & $x^{2}$ & $p$ & $x^{2}$ & $P$ & $x^{2}$ & $p$ & $x^{2}$ & $p$ & $x^{2}$ & $P$ & $x^{2}$ & $p$ & $x^{2}$ & $p$ \\
\hline $\begin{array}{l}\text { OVERALL } \\
\text { IES }\end{array}$ & 8.000 & $0.018^{*}$ & 2.000 & 0.368 & 1.600 & 0.449 & 0.333 & 0.846 & 9.333 & $0.009 *$ & 8.400 & $0.015 *$ & 6.000 & $0.050 *$ & 4.222 & 0.121 \\
\hline $\begin{array}{l}\text { Continuous } \\
\text { Learning }\end{array}$ & 3.231 & 0.199 & 0.857 & 0.651 & 2.000 & 0.368 & 2.333 & 0.311 & 1.000 & 0.607 & 1.200 & 0.549 & 6.500 & $0.039 *$ & 4.222 & 0.121 \\
\hline $\begin{array}{l}\text { Self- } \\
\text { Awareness }\end{array}$ & 7.277 & $0.026 *$ & 0.095 & 0.953 & 6.500 & $(0.039)^{*}$ & 0.737 & 0.692 & 0.636 & 0.727 & 5.444 & 0.066 & 3.000 & 0.223 & 5.543 & 0.063 \\
\hline Exploration & 3.957 & 0.138 & 1.040 & 0.595 & 4.133 & 0.127 & 1.333 & 0.513 & 1.600 & 0.449 & 0.105 & 0.949 & 4.500 & 0.105 & 3.063 & 0.216 \\
\hline $\begin{array}{l}\text { Interpersonal } \\
\text { Engagement }\end{array}$ & 7.412 & $0.025 *$ & 1.407 & 0.495 & 7.600 & $0.022 *$ & 0.000 & 1.000 & 6.333 & $0.042 *$ & 6.400 & $0.041 *$ & 1.500 & 0.472 & 6.889 & $0.032 *$ \\
\hline $\begin{array}{l}\text { Global } \\
\text { Mindset }\end{array}$ & 10.957 & $0.004 *$ & 1.407 & 0.495 & 6.421 & $0.040^{*}$ & 2.211 & 0.331 & 6.522 & $0.038^{*}$ & 5.158 & 0.076 & 4.133 & 0.127 & 3.257 & 0.196 \\
\hline $\begin{array}{l}\text { Relationship } \\
\text { Interest }\end{array}$ & 3.191 & 0.203 & 0.750 & 0.687 & 0.824 & 0.662 & 2.174 & 0.337 & 4.727 & 0.094 & 2.632 & 0.268 & 4.133 & 0.127 & 2.970 & 0.227 \\
\hline Hardiness & 3.640 & 0.162 & 1.143 & 0.565 & 0.105 & 0.949 & 0.091 & 0.956 & 5.478 & 0.065 & 0.737 & 0.692 & 3.500 & 0.174 & 1.556 & 0.459 \\
\hline $\begin{array}{l}\text { Positive } \\
\text { Regard }\end{array}$ & 4.275 & 0.118 & 2.889 & 0.236 & 0.933 & 0.627 & 1.826 & 0.401 & 4.957 & 0.084 & 0.111 & 0.946 & 2.800 & 0.247 & 0.727 & 0.695 \\
\hline $\begin{array}{l}\text { Emotional } \\
\text { Resilience }\end{array}$ & 2.520 & 0.284 & 3.630 & 0.163 & 2.211 & 0.331 & 1.182 & 0.554 & 3.739 & 0.154 & 2.800 & 0.247 & 1.273 & 0.529 & 0.000 & 1.000 \\
\hline LOCATION & \multicolumn{2}{|c|}{$\begin{array}{c}\text { Peru } \\
(\mathrm{N}=13)\end{array}$} & \multicolumn{2}{|c|}{$\begin{array}{l}\text { Ghana } \\
(\mathrm{N}=7)\end{array}$} & \multicolumn{2}{|c|}{$\begin{array}{l}\text { China } \\
(\mathrm{N}=5)\end{array}$} & \multicolumn{2}{|c|}{$\begin{array}{c}\text { France; } \\
\text { Netherlands } \\
(\mathrm{N}=6)\end{array}$} & \multicolumn{2}{|c|}{$\begin{array}{c}\text { Italy } \\
(\mathrm{N}=6)\end{array}$} & \multicolumn{2}{|c|}{$\begin{array}{l}\text { Mexico } \\
(\mathrm{N}=5)\end{array}$} & \multicolumn{2}{|c|}{$\begin{array}{c}\text { Germany; } \\
\text { Austria } \\
(\mathrm{N}=4)\end{array}$} & \multicolumn{2}{|c|}{$\begin{array}{l}\text { Europe } \\
(\mathrm{N}=9)\end{array}$} \\
\hline
\end{tabular}

Note: $d f=2 ; *$ Significance at $p<0.05$ level

Due to the size of each program, there are limitations to the generalizability of the data. Still, a one-way ANOVA was conducted to test for between program differences on the pre-trip mean scores. Among all ten scales provided by the IES instrument, only Global Mindset showed a significant difference $\left(F(7)=2.534, \eta^{2}=0.274, p=.027\right)$. In this case, mean scores for the Europe Program traveling to six countries had participants that started with significantly higher Global Mindset scores when compared to the program going to China. Having students with noticeably higher mean scores for certain subscales in the Europe Program may have indicated a distinction in the type of participant based on field of study, where the program focused on political science and international relations. It may also have limited the gains made or suggest the need for a more sophisticated model of intervention for intercultural development. 
Program activities and assignments. To understand the types of development seen within the IES for all fifty-five students, it is useful to look at the relationship between program assignments and activities and the IES intercultural competencies: Self-Awareness, Exploration, Global Mindset, Relationship Interest, Positive Regard, and Emotional Resilience. It is difficult to draw direct correlations since such activities or assignments could encompass multiple competencies and were limited to descriptions provided by the program syllabi. Still, the activities and assignments within each program were coded to match based on their association with one or more intercultural competencies in the IES. Table 6 outlines the percentage of total activities in each program that connected to these competencies including those areas of overlap that may occur. Most planned activities focused on cultural exploration of sites, cultural knowledge, and engagement with or discussion of cultural differences. The assignments for documenting such experiences focused on reflection, observation, and written or verbal discussion of cultural knowledge and cultural difference.

Table 6. Percentage of Program Activities and Assignments related to Intercultural Competencies

\begin{tabular}{|c|c|c|c|c|c|c|c|}
\cline { 3 - 8 } \multicolumn{2}{c}{} & \multicolumn{5}{c|}{ Intercultural Competencies } \\
\hline \multirow{2}{*}{ Program } & $\begin{array}{c}\text { Syllabus } \\
\text { Activities \& } \\
\text { Assignments }\end{array}$ & $\begin{array}{c}\text { Self- } \\
\text { Awareness }\end{array}$ & Exploration & $\begin{array}{c}\text { Global } \\
\text { Mindset }\end{array}$ & $\begin{array}{c}\text { Relationship } \\
\text { Interest }\end{array}$ & $\begin{array}{c}\text { Positive } \\
\text { Regard }\end{array}$ & $\begin{array}{c}\text { Emotional } \\
\text { Resilience }\end{array}$ \\
\hline Peru & 16 & $6 \%$ & $\mathbf{9 4 \%}$ & $\mathbf{8 1 \%}$ & $13 \%$ & $6 \%$ & $6 \%$ \\
\hline Ghana & 32 & $13 \%$ & $\mathbf{6 9 \%}$ & $\mathbf{8 1 \%}$ & $13 \%$ & $3 \%$ & $0 \%$ \\
\hline Netherlands; France & 33 & $6 \%$ & $\mathbf{5 8 \%}$ & $\mathbf{9 7 \%}$ & $0 \%$ & $0 \%$ & $0 \%$ \\
\hline China & 35 & $11 \%$ & $\mathbf{6 9 \%}$ & $\mathbf{9 7 \%}$ & $20 \%$ & $3 \%$ & $0 \%$ \\
\hline Italy & 29 & $10 \%$ & $\mathbf{9 7 \%}$ & $\mathbf{7 2 \%}$ & $14 \%$ & $3 \%$ & $0 \%$ \\
\hline Mexico & 30 & $23 \%$ & $\mathbf{7 7 \%}$ & $\mathbf{9 0 \%}$ & $47 \%$ & $3 \%$ & $3 \%$ \\
\hline $\begin{array}{c}\text { Germany, Austria } \\
\text { Purkey, Germany, }\end{array}$ & 47 & $6 \%$ & $\mathbf{6 2 \%}$ & $\mathbf{1 0 0 \%}$ & $13 \%$ & $2 \%$ & $0 \%$ \\
$\begin{array}{c}\text { Austria, Czech } \\
\text { Republic }\end{array}$ & 72 & $1 \%$ & $\mathbf{5 3 \%}$ & $\mathbf{9 3 \%}$ & $4 \%$ & $1 \%$ & $0 \%$ \\
\hline
\end{tabular}

While each of the competencies may require different levels of activity or engagement to be affected, this analysis of program content offers a base from which to understand which areas these faculty-led programs concentrated their efforts. Given the spread of activities and assignments, the documents seemed to support the more immediate changes in the IES competencies from pre to post experience, where the majority of significant changes were seen in Self-Awareness and Global Mindset (with some upward trend in Exploration). Self-Awareness was encompassed mainly by reflection journals that varied between programs as to whether they were daily, during, or post study abroad. Although considered one assignment in terms of percentage, these journals usually included extended engagement across the study abroad experience. That all programs had more than $70 \%$ of activities concentrated on Global Mindset seems to support the changes seen in the IES with strong effect sizes that were sustained three months later. Exploration, on the other hand often covered more than $50 \%$ of activities, but did not reach significance. The drop in Exploration could be a factor of students leaving the more immersive environments in which they could naturally explore new cultures and may indicate the need for clearly linked activities upon reentry. 
Relationship Interest, which only became significant after development over three months may be a product of the activities and assignments providing a seed for students to begin building and maintaining such relationship interest with their new international contacts over time. Several programs offered meaningful opportunities that allowed students to make international connections. Two of the eight programs had specific partnerships with local students built into the program and all eight programs included at least one planned activity involving local interactions and discussions with a local community, business, or student group. For example, the program in Ghana and the program through six countries in Europe both had a planned roundtable discussion with local graduate students or young academics. Taking that a step further, the program to China gave each student a buddy from the university with which it was partnering. Not only were these buddies a part of the students' free time activities in Beijing, but they also communicated with each other by email in the three months leading up to the travel. At a more extensive level, the program to Mexico had projects where each of the student groups worked with at least two other Mexican university students, one of whom worked as translator for the group. These groups worked together for the four weeks creating and developing a narrative story as part of their journalism project. Students participating in the Mexico program also spent two of the four weeks with a host family in the area where they were searching for a story. While there were structured and unstructured intercultural interactions, many of those interactions focused on communication of cultural difference and not necessarily on activities for continuing those interactions after the program finished. Therefore, the three months following the experience may have been necessary for students to build behaviors for maintaining those relationships, though it is difficult to presume that participating in study abroad alone led to significant gains three months later.

The lack of activities or assignments related to Positive Regard and Emotional Resilience is most telling in that those competencies did not see measured significant changes as a product of these intercultural experiences. Most programs had no activities or assignments intended to assist in attitudes of positive regard or build mental strength; instead, programs aimed to encourage more cognitive experiences for understanding other cultures and cultural differences.

Due to the complexity of this phenomenon, one could not clearly say that these particular activities or assignments would produce assured development of intercultural competency. What the IES and documents do appear to support is intentionality in program design. Intercultural competency and growth can occur in short periods if programs are structured in ways that target desired intercultural competencies. The continued development of those competencies will require not just meaningful reflection during or soon after the experience, but continued engagement by the program or the institution.

\section{Implications for Practice}

This research indicates the capacity of short-term study abroad programs ranging from two to five weeks to have significant impacts on students' self-perceived intercultural competency. The IES data measured significant gains in students' overall intercultural competency that was maintained three months later following participation in short-term study abroad experience; this change was mainly influenced by three of the six IES competencies (Self-Awareness, Global Mindset, and Relationship Interest). In addition, document analysis suggests that programs are aided by providing structured activities or assignments associated with those areas of the IES concerned with acquiring 
cultural knowledge and understanding cultural difference. Though there were of course limitations to this study, these findings illustrate gains as measured by the IES and opens the question as to how faculty leaders can better understand and design short-term programs to ensure students' intercultural development by having reflective and engaging activities and assignments.

Moving forward, educational leaders should consider what this means not only for the strategic development of short-term programs, but also the integration of those programs as part of larger institutional goals. There is a clear implication that areas of intercultural competence most affected are those targeted by activities specific to those learning outcomes. In terms of developing those intercultural experiences, findings align with recommended practices for educators to structure activities in combination with guided reflection and clear intercultural objectives (Braskamp, Braskamp, \& Merrill 2009; Donnelly-Smith, 2009; Mills, Deviney, \& Ball, 2010, Tarrant, Rubin, \& Stoner, 2014), to incorporate opportunities for meaningful and immersive local interaction (Donnelly-Smith, 2009; Lewis \& Niesenbaum, 2005b; Spencer \& Tuma, 2002), and to provide planned re-entry (Behrnd \& Porzelt, 2012; Huq \& Lewis, 2012; Mills et al., 2010; Paige, Fry, Stallman, Josić, \& Jon, 2009).

These practices are seen in how activities and assignments were connected to specific areas of intercultural competence. The programs' objectives for understanding different cultural contexts led to designing activities such as cultural site visits or lectures on comparative differences that concentrated on Global Mindset. In terms of Self-Awareness, reflection was a common activity that offered students a way to reevaluate and later re-contextualize their experiences. Whether during or after the study abroad, students were given time to reflect on and process their experiences. Though each program offered a different model of interaction related to Relationship Interest, intentional decisions were made to allow students opportunities to engage with the local community through roundtables, partner projects, and other shared activities unique to each site that would be hard to emulate on campus. As for maintaining gains that students have made as a part of these short-term study abroad programs, it needs to be considered not just at a programmatic level, but at an institutional level. Strategies for re-entry should be included to sustain the heightened state of intercultural awareness and other gains made following short-term study abroad programs. It does appear that short-term programs positively impact students, but these experiences are just one point of intervention in an ongoing process for students to develop intercultural competence.

The challenge for educational leaders will be first and foremost to determine their objectives for students in developing intercultural competence and their intended purpose for short-term study abroad programs as a part of that development. Though a variety of options and models for shortterm study abroad programs exist (Mills et al., 2010), well-defined and intentional programmatic structures are essential to student growth in intercultural competence within the unique environments of study abroad. The Institute of International Education has stated that "shorter programs, if well planned, can offer a more intensive and focused experience-and may be the only realistic alternative in terms of the demands of [student] degree studies and economic resources" (as cited in Long, et al., 2010, p. 92). To give the most benefit to students, short-term study abroad design should have a clear vision of intercultural learning outcomes with intentional programmatic structures that also continue to develop those competencies after the program has completed and as part of a larger institutional culture. 
Perhaps the most serious limitation of this research endeavor is the sample size and variety of factors, which are too few and too many to say with certainty what programmatic structures best support intercultural growth. Still, there is evidence here that short-term study abroad programs, even as short as two weeks, provide meaningful educational experiences leading to measurable gains in intercultural competency. Future research could use broader samples or more focused case studies over longer periods of time. Other considerations might include research on intercultural growth of students participating in multiple short-term study abroad programs, impacts of institutional level re-entry programs, and development of intercultural competence as a part of ongoing global engagement long after graduation. As institutions continue to work toward campus internationalization, there is more that can be learned about the impacts of short-term study abroad and how best to support them as meaningful endeavors for cultivating intercultural competence.

\section{REFERENCES}

Anderson, P. H, Lawton, L., Rexeisen, R. J., \& Hubbard, A. C. (2006). Short-term study abroad and intercultural sensitivity: A pilot study. International Journal of Intercultural Relations, 30(4), 457469.

Association of American Colleges and Universities. (2010). Intercultural Knowledge and Competence VALUE Rubric. Retrieved from http://www.aacu.org/value/rubrics/pdf/InterculturalKnowledge.pdf

Behrnd, V. \& Porzelt, S. (2012). Intercultural competence and training outcomes of students with experiences abroad. International Journal of Intercultural Relations, 36(2), 213-223.

Bennett, J. M. (2009). Transformative Training: Designing Programs for Cultural Learning. In M. A. Moodian (Ed.), Contemporary leadership and intercultural competence: Exploring the cross-cultural dynamics within organizations (pp. 95-110). Los Angeles, CA: SAGE.

Bennett, M. J. (1993). Towards ethnorelativism: A development model of Intercultural Experience. In R. M. Paige (Ed.). Education for the Intercultural Experience (pp. 27-71). Yarmouth, ME: Intercultural Press.

Bird, A., Mendenhall, M., Stevens, M. J., \& Oddou, G. (2010). Defining the content domain of intercultural competence for global leaders. Journal of Managerial Psychology, 25(8), 810-828.

Bird, A., Stevens, M., Mendenhall, M., Oddou, G., \& Osland, J. S. (2008). The Intercultural Effectiveness Scale. St. Louis, MO: The Kozai Group, Inc.

Bird, A. \& Stevens, M. J. (2013) Assessing Global Leadership Competencies. In Mendenhall, M. E., Osland, J. S., Bird, A., Oddou, G. R., Maznevski, M. L., Stevens, M. J., \& Stahl, G. K. (Eds.), Leadership 2e: Research, Practice, and Development (pp. 113-140). New York NY: Routledge.

Bok, D. (2006). Our Underachieving Colleges. Princeton, NJ: Princeton University Press.

Braskamp, L. A., Braskamp, D., \& Merrill, K. (2009). Assessing progress in global learning and development of students with education abroad experiences. Frontiers: The Interdisciplinary Journal of Study Abroad, 18, 101-118.

Chieffo, L., \& Griffiths, L. (2004). Large-Scale Assessment of Student Attitudes after a Short-Term Study Abroad Program. Frontiers: The interdisciplinary journal of study abroad, 10, 165-177.

Costa, P. \& McCrae, R. (1985). The NEO Personality Inventory: Manual, Form S and Form R. Lutz, FL: Psychological Assessment Resources.

Deardorff, D. K. (2006). Identification and assessment of intercultural competence as a student outcome of internationalization. Journal of studies in international education, 10(3), 241-266.

Deardorff, D. K. (2011), Assessing intercultural competence. New Directions for Institutional Research, 2011(149), 65-79.

Deardorff, D. K. \& Hunter, W. (2006). Educating global-ready graduates. International Educator, 15(3), 72-83.

Donnelly-Smith, L. (2009). Global learning through short-term study abroad. Peer Review, 11(4), 12. 
Dwyer, M. M. (2004). More Is Better: The Impact of Study Abroad Program Duration. Frontiers: The Interdisciplinary Journal of Study Abroad, 10, 151-163.

Earley, P. C. \& Ang, S. (2003). Cultural Intelligence: Individual Interactions across Cultures. Stanford, CA: Stanford University Press.

Feng, J. B. (2016). Improving Intercultural Competence in the Classroom: A Reflective Development Model. Journal of Teaching in International Business, 27(1), 4-22.

Fish, K. (2013). Increasing Intercultural Effectiveness Through a Global Citizenship Approach. Administrative Issues Journal, 3(3), 15-18.

Gertsen, M. C. (1990). Intercultural competence and expatriates. The International Journal of Human Resource Management, 1(3), 341-362.

Gowindasamy, M. (2017). A Case Study on the Implementation of Reflective Development Model in Improving Intercultural Competence among Business Student in Stamford College. Journal of Education and Practice, 8(12), 168-174.

Green, M. F. (2012). Global Citizenship: What Are We Talking About and Why Does it Matter?. International Educator, 21(3), 124-127.

Hulstrand, J. (2006). Education Abroad on the Fast Track. International Educator, 15(3), 46-55.

Hunter, W. (2004). Knowledge, Skills, Attitudes, and Experiences Necessary to Become Globally Competent. Unpublished Dissertation. Lehigh University, Bethlehem, PA.

Hunter, A. (2008). Transformative learning in international education. In V. Savicki (Ed.), Developing intercultural competence and transformation: Theory, research, and application in international education (pp. 92-107). Sterling, VA: Stylus.

Huq, J. \& Lewis, L. (2012). From Collaboration to Campus-Wide Partnership. International Educator (1059-4221), 21(4), 46-51.

IES Abroad. (2011 May 10). Rise in Enrollment for Short-term Study Abroad Customized Programs at IES Abroad Echoes National Trend [Press release]. Retrieved from http://www.prweb.com/releases/2011/5/prweb8404836.htm

Institute of International Education. (2011). U.S. Campuses Report that Study Abroad is Rising [Press release]. Retrieved from http://www.iie.org/Who-We-Are/News-and-Events/Press-Center/PressReleases/2011/2011-11-14-Open-Doors-Fall-Survey-Study-Abroad

Institute of International Education (2016). Open Doors Report. IIE.org. Retrieved from www.iie.org/opendoors.

Intercultural Effectiveness Scale (IES). (2013). KozaiGroup.com. Retrieved from http://kozaigroup.com/inventories/the-intercultural-effectiveness-scale/

Jackson, J. (2008). Globalization, internationalization, and short-term stays abroad. International Journal of Intercultural Relations, 32(4), 349-358.

Javidan, M. \& Bowen, D. (2013). The 'Global Mindset' of managers: What it is, why it matters, and how to develop it. Organizational Dynamics, 42(2), 145-155.

Kehl, K., \& Morris, J. (2007). Differences in global-mindedness between short-term and semester-long study abroad participants at selected private universities. Frontiers: The Interdisciplinary Journal of Study Abroad, 15, 67-79.

Kelley, C. \& Meyers, J. (1995). The Cross-cultural Adaptability Inventory. Minneapolis, MN: National Computer Systems.

Kim, Y. Y. (2001). Becoming intercultural: An integrative theory of communication and cross-cultural adaptation. Thousand Oaks, CA: Sage.

Lewis, T.L., \& Niesenbaum, R.A. (2005a). Extending the stay: Using community-based research and service learning to enhance short-term study abroad. Journal of Studies in International Education, 9(3), 251-264.

Lewis, T. L., \& Niesenbaum, R. A. (2005b). The benefits of short-term study abroad. Chronicle of Higher Education, 51(39), B20. 
Long, S. O., Akande, Y. S., Purdy, R. W., \& Nakano, K. (2010). Deepening Learning and Inspiring Rigor: Bridging Academic and Experiential Learning Using a Host Country Approach to a Study Tour. Journal of Studies in International Education, 14(1), 89-111.

Medina-López-Portillo, A. (2004). Intercultural Learning Assessment: The Link between Program Duration and the Development of Intercultural Sensitivity. Frontiers: The Interdisciplinary Journal of Study Abroad, 10, 179-199.

Mendenhall, M. E., Stevens, M. J., Bird, A., Oddou, G. R., \& Osland, J. S. (2012). Intercultural Effectiveness Scale Technical Report. Chesterfield, MO: The Kozai Group, Inc.

Mills, L. H., Deviney, D., \& Ball, B. (2010). Short-term study abroad programs: A diversity of options. The Journal of Human Resource and Adult Learning, 6(2), 1-13.

Olson, C. L., Green, M. F., \& Hill, B. A. (2006). A handbook for advancing comprehensive internationalization: What institutions can do and what students should learn. Washington, DC: American Council on Education.

Paige, R. M., Fry, G. W., Stallman, E. M., Josić, J., \& Jon, J. E. (2009). Study abroad for global engagement: The long-term impact of mobility experiences. Intercultural Education, 20(sup1), S29S44.

Pedersen, P. J. (2010). Assessing intercultural effectiveness outcomes in a year-long study abroad program. International Journal of Intercultural Relations, 34(1), 70-80.

Richards, C. A., \& Doorenbos, A. Z. (2016). Intercultural competency development of health professions students during study abroad in India. Journal of Nursing Education and Practice, 6(12), 89.

Robinson, J., Harrington, M., Cartwright, C., \& Walsh, K. (2017). Connective Leadership: From ZeroSum to Inclusion. In A. Boitano, R. L. Dutra, H. E. Schockman (Eds.), Breaking the Zero-Sum Game: Transforming Societies through Inclusive Leadership (pp. 209-225). Bingley, UK: Emerald Publishing Limited.

Schaettim, B. F., Ramsey, S. J., \& Watanabe, G. C. (2009). From Intercultural Knowledge to Intercultural Competence: Developing an Intercultural Practice. In M. A. Moodian (Ed.), Contemporary leadership and intercultural competence: Exploring the cross-cultural dynamics within organizations (pp. 125-144). Los Angeles, CA: SAGE.

Spencer, S. E., \& Tuma, K. (Eds.). (2002). The guide to successful short-term programs abroad. Washington, DC: NAFSA: Association of International Educators.

Stebleton, M. J., Soria, K. M., \& Cherney, B. T. (2013). The High Impact of Education Abroad: College Students' Engagement in International Experiences and the Development of Intercultural Competencies. Frontiers: The Interdisciplinary Journal of Study Abroad, 22, 1-24.

Tarrant, M. A., Rubin, D. L., \& Stoner, L. (2014). The Added Value of Study Abroad Fostering a Global Citizenry. Journal of Studies in International Education, 18(2), 141-161.

van der Zee, K. \& van Oudenhoven, J. P. (2000). The multicultural personality questionnaire: A multidimensional instrument of multicultural effectiveness. European Journal of Personality, 14, 291-309.

van der Zee, K. \& Brinkman, V. (2004). Construct validity evidence for the Intercultural Readiness Check against the Multicultural Personality Questionnaire. International Journal of Selection and Assessment, 12(3), 285-290.

Vande Berg, M., Connor-Linton, J., \& Paige, R. M. (2009). The Georgetown consortium project: Interventions for student learning abroad. Frontiers: The Interdisciplinary Journal of Study Abroad, $18,1-75$.

Vande Berg, M., Paige, R. M., \& Lou, K. H. (2012). Student learning abroad: What our students are learning, what they're not, and what we can do about it. Sterling, VA: Stylus Publishing, LLC. 